\title{
The Metabolism of Progesterone by Animal Tissue in vitro
}

\section{FACTORS INFLUENCING THE METABOLISM OF PROGESTERONE BY RABBIT LIVER AND THE INVESTIGATION OF THE PRODUCTS OF METABOLISM*}

\author{
BY W. TAYLOR \\ Department of Physiology, The Medical School, King's College, University of Durham, Newcastle upon Tyne
}

(Received 22 December 1954)

In the first paper of this series (Taylor, 1954a), it was shown that progesterone metabolism by ratliver homogenate is increased by addition of either diphosphopyridine nucleotide (DPN) or nicotinamide (or both) or of citrate to the incubation medium; metabolism is not inhibited under anaerobic conditions. In a large-scale experiment, $28 \%$ of the progesterone incubated with rat-liver homogenate (prepared in nicotinamide solution) was accounted for by isolation of $5 \alpha$-pregnane-3:20 . dione, $3 \alpha$-hydroxy-5 $\alpha$-pregnan-20-one, unchanged progesterone, and an unidentified substance which was probably not a 'pregnanediol'. The failure to isolate any steroids of the $5 \beta$-pregnane series was rather disconcerting in view of the fact that in humans and many other animals the reduction products of progesterone appearing in the urine are mainly of this series (see Dorfman \& Ungar, 1953, for references). The metabolites of progesterone produced by the rat in vivo have not been fully characterized, but Riegel, Hartop \& Kittinger (1950) demonstrated that after injection of $\left[21-{ }^{14} \mathrm{C}\right]-$ progesterone into rats, most of the radioactivity was found in the faeces in a ketonic, non-alcoholic, neutral steroid which was not progesterone. It has not been established whether or not the rat excretes 'pregnanediols' normally or after progesterone administration.

It seemed desirable, therefore, to investigate the in vitro metabolism of progesterone by the liver of the rabbit, since this animal excretes $5 \beta$-pregnane$3 \alpha: 20 \alpha$-diol (the principal urinary metabolite of progesterone in humans) in the urine during pregnancy and after mating (Verly, Sommerville \& Marrian, 1950) and after progesterone administration (Heard, Bauld \& Hoffman, 1941; Hoffman, 1942; Westphal, 1942) and in the faeces after oral but not subcutaneous administration of the hormone (Hoffman \& Browne, 1942).

The metabolism of progesterone by rabbit-liver preparations has now been investigated. It has been shown that the enzyme system in rabbit liver is similar to that of rat liver in that metabolism is increased by addition of DPN and nicotinamide or of citrate to the reaction mixture and is not in-

* Part 1 of this series Taylor, 1954, 56, 463. hibited under anaerobic conditions. The aim of these experiments was to obtain a system of optimum activity which could be used for the isolation of the products of metabolism.

In a large-scale experiment in which progesterone was incubated in air with a suspension of disintegrated rabbit liver with nicotinamide and citrate added, the following steroids were isolated: $5 \alpha-$ pregnane-3:20-dione, the $3 \alpha$ - and $3 \beta$-hydroxy-5 $\alpha$ pregnan-20-ones, $3 \alpha$-hydroxy-5 $\beta$-pregnan-20-one and $5 \beta$-pregnane-3 $\alpha: 20 \alpha$-diol. (See Fig. 3, p. 385.) Approximately $33 \%$ of the incubated progesterone was accounted for as metabolites or unchanged progesterone. From the 'control', $52 \%$ of the added progesterone was recovered.

A preliminary account of part of this work has already appeared (Taylor, 1954b).

\section{EXPERIMENTAL}

\section{Materials and methods}

The methods employed for the preparation of slices and homogenates, determination of progesterone and the arrangement of quantitative experiments and for the purification of the Celite and solvents used in partition and adsorption chromatography were as described in a previous publication (Taylor, 1954 $a$ ) except where otherwise stated.

Experimental animals were male or female rabbits, approx. 1 year old, of various strains; they were not bred in the laboratory but were purchased as required. It was demonstrated in separate experiments (unpublished) that the sex of the animal did not influence the results. The animals were killed by a blow on the neck and the livers were rapidly removed, washed in ice-cold $0.15 \mathrm{M}-\mathrm{KCl}$ and then dried on filter paper.

Since no temperature-controlled room was available in these laboratories for partition chromatography, equilibration of solvents and running of columns were carried out in a water-jacketed cabinet maintained at $18 \pm 2^{\circ}$. In adsorption chromatography, alumina (Savory and Moore Ltd., London) was activated by heating in shallow dishes at $130^{\circ}$ for $12 \mathrm{hr}$. The amounts of alumina and dimensions of columns were as recommended by Reichstein \& Shoppee (1949). For gradient elution of adsorption columns, an apparatus similar to that described by Lakshmanan (1954) was employed. Progesterone eluted from partition columns was determined by measuring its selective absorption at $240 \mathrm{~m} \mu$. in ethanol in a Uvispek spectrophotometer (Hilger and Watts Ltd.; Model H 700/303). 
For the determination of absorption spectra in $\mathrm{H}_{2} \mathrm{SO}_{4}$, isolated material and authentic steroid samples (90-110 $\mu \mathrm{g}$. each) in glass-stoppered tubes were treated with $3 \mathrm{ml}$. conc. $\mathrm{H}_{2} \mathrm{SO}_{4}$ (A.R.) for $2 \mathrm{hr}$. at $18-20^{\circ}$ with occasional shaking. Spectra were then determined in $1.0 \mathrm{~cm}$. cells over the range 220-520 m $\mu$. in a Unicam SP. 500 spectrophotometer.

Infrared spectra were determined in $\mathrm{CS}_{2}$ solution in a double-beam Perkin-Elmer $21 \mathrm{~B}$ spectrophotometer over the range $800-4000 \mathrm{~cm}^{-1}$.

\section{RESULTS}

The results of incubating progesterone with rabbitliver preparations under a variety of conditions are illustrated in Figs. 1 and 2. It may be seen that progesterone is metabolized by rabbit liver and that (a) slices are more active than homogenate, (b) activity of homogenates is increased by addition of

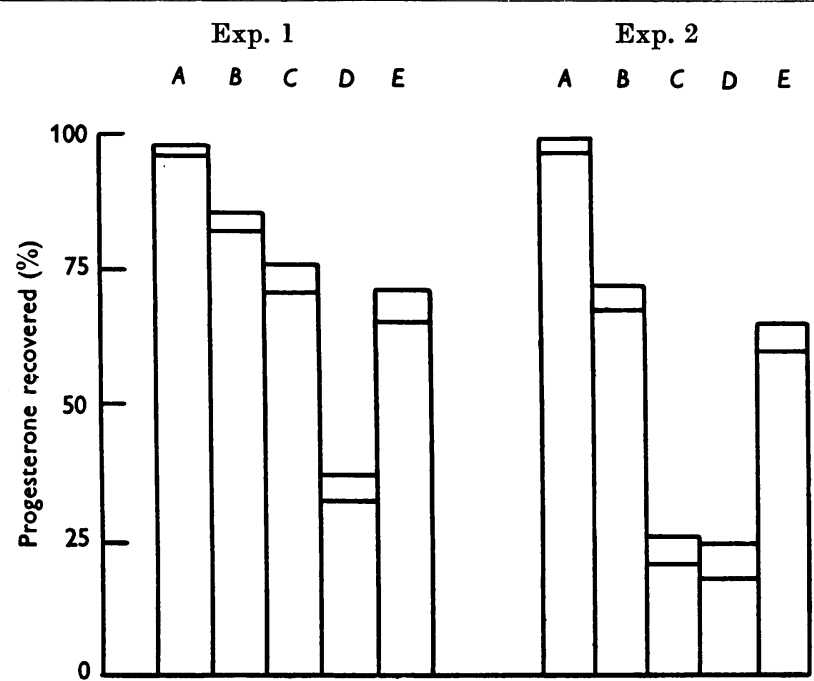

Fig. 1

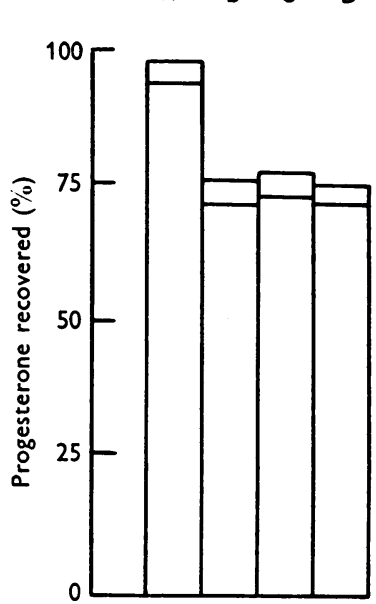

Fig. 2

Fig. 1. Incubation of progesterone with rabbit-liver slices and homogenate. Basic reaction mixture: $0.5 \mathrm{mg}$. progesterone in $0.05 \mathrm{ml}$. propylene glycol, $2.0 \mathrm{ml}$. 'phosphate saline', $1 \mathrm{ml} .0 .15 \mathrm{M}-\mathrm{KCl}+$ liver as slices or homogenate. Expt. 1 , $250 \mathrm{mg}$. liver; Expt. 2, $500 \mathrm{mg}$. liver. Progesterone recovered: $A$, from controls; after incubation- $B$, with homogenate; $C$, with slices; $D$, with homogenate plus added nicotinamide and DPN (final concs.: Expt. 1, 40 and 2.0 mM and Expt. 2, 80 and 4.0 mM, respectively); $E$, with homogenate plus added citrate, final conc., 1.0 mM. In this type of figure, double lines at ends of bars indicate duplicate values.

Fig. 2. Incubation of progesterone with rabbit-liver slices. Effect of anaerobic conditions. Reaction mixture: 0.5 mg. progesterone in $0.05 \mathrm{ml}$. propylene glycol, $2.0 \mathrm{ml}$. 'phosphate-saline', $1.0 \mathrm{ml} .0 .15 \mathrm{M}-\mathrm{KCl}$ and $250 \mathrm{mg}$. slices. Progesterone recovered: $A$, from controls; after incubation- $B$, in air; $C$, in nitrogen; $D$, in evacuated Thunberg tube.

Pyridine (A.R.) was allowed to stand over $\mathrm{KOH}$ pellets for at least a week and distilled immediately prior to use. Digitonin and Girard Reagent $T$ (both from British Drug Houses Ltd.) were used without further purification. Semicarbazide hydrochloride was recrystallized twice from aqueous ethanol before use.

Reference steroids. Progesterone, a commercial sample, was recrystallized from $n$-hexane and aqueous ethanol and had m.p. 120-121.5 . 5 $\alpha$-Pregnane-3:20-dione and $3 \alpha$ hydroxy-5 $\alpha$-pregnan-20-one were the preparations already described (Taylor, 1954a); the acetate of the latter was obtained from Dr H. Hirschmann, Lakeside Hospital, Cleveland, Ohio. 3 $\beta$-Hydroxy-5 $\alpha$-pregnan-20-one and its acetate were gifts from Dr J. Y. F. Paterson, University of Liverpool. 3 $\alpha$-Hydroxy-5 $\beta$-pregnan-20-one was prepared from the ketonic fraction of sodium 'pregnanediol' glucuronidate as described by Marrian \& Gough (1946) and Sutherland \& Marrian (1947). Professor G. F. Marrian supplied samples of 5 $\beta$-pregnane-3 $\alpha: 20 \alpha$-diol and its 3:20diacetate.
DPN and nicotinamide or of citrate and (c) metabolism by slices is not reduced in the absence of oxygen. Thus, the enzyme system present in rabbit liver appears to be similar to that in rat liver. Rabbit liver, however, is not so active, weight for weight, as rat liver in metabolizing progesterone nor does citrate have such a marked stimulatory effect on rabbit liver as it does on rat liver (cf. Taylor, $1954 a)$.

Because of this lower activity of rabbit liver, it was considered desirable to increase the tissue: steroid ratio in a large-scale experiment to at least $1000: 1$. The large amount of liver required for incubation of approximately $300 \mathrm{mg}$. steroid and for a 'control' experiment rendered impracticable the preparation of the homogenate in a Potter-type homogenizer since that available had a capacity of only 3-4 g. tissue. The Waring Blendor type of 
homogenizer with high-speed rotating blades is considered unsuitable for many types of enzyme preparation, and for reasons already discussed (Taylor, 1954a), such a Blendor was not used for the large-scale experiment with rat liver. Preliminary experiments (not reported here) with the similar Atomix blender (Measuring and Scientific Equipment Ltd., London) indicated that suspensions of disintegrated tissue ('suspensions') prepared in this apparatus were able to metabolize progesterone. Such 'suspensions', however, were less active than homogenates prepared in the nylon-glass, piston-type homogenizer previously described (Taylor, 1954a). In a typical experiment in which progesterone was incubated with 'suspension' or homogenate from the same liver with added citrate and nicotinamide, $35 \%$ progesterone was recovered from the 'suspension' and $5 \%$ from the homogenate; the tissue:steroid ratio was $1200: 1$.

\section{Investigation of the products of metabolism}

Preparation of tissue suspension. The liver was chopped finely with scissors and $50 \mathrm{~g}$. portions were homogenized for $2 \mathrm{~min}$. at high speed in the chilled blender, which contained $50 \mathrm{mi}$. $0 \cdot 15 \mathrm{M}-\mathrm{KCl}$ containing $0.24 \mathrm{M}$ nicotinamide. The resulting 'suspension' after filtering through gauze, was made up to $80 \mathrm{ml}$. with $\mathrm{KCl}$-nicotinamide solution and kept at $0^{\circ}$ until added to incubation flasks.

Incubation. Incubations were carried out in $100 \mathrm{ml}$. conical flasks containing $20 \mathrm{ml}$. 'phosphate

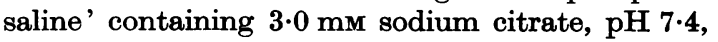
$10 \mathrm{ml}$. liver 'suspension' (equivalent to approx. $6 \mathrm{~g}$. tissue) and $0.5 \mathrm{ml}$. propylene glycol solution of progesterone $(10 \mathrm{mg} . / \mathrm{ml}$.). Pure solvent $(0.5 \mathrm{ml}$.) was added to 'control' flasks. Thus, the final reaction mixture contained approx. $80 \mathrm{~mm}$ nicotinamide, $2.0 \mathrm{~mm}$ citrate and the tissue: steroid ratio was $1200: 1$. The flasks were not stoppered but were shaken vigorously during the incubation for $2 \mathrm{hr}$. at $37^{\circ}$. In this manner a total of $370 \mathrm{mg}$. progesterone were incubated with approx. $450 \mathrm{~g}$. liver while for the 'control', $370 \mathrm{mg}$. progesterone were added after incubation of the same amount of liver.

Lipid extracts. The neutral lipid extract was then prepared in the manner described for the largescale experiment with rat liver (Taylor, 1954a), with appropriate increase in quantities of solvents for the larger scale of the present experiment. The purification involved removal of protein by acetone precipitation, extraction of the aqueous residue, after evaporation of the acetone, with ethyl acetate, partition between $75 \%(v / v)$ aqueous methanol: hexane and finally chloroform extraction of the aqueous residue after removal of the methanol by distillation in vacuo.
The incubation and 'control' extracts, dried in a vacuum desiccator over $\mathrm{P}_{2} \mathrm{O}_{5}$ for $24 \mathrm{hr}$. were heated under reflux condenser for $2 \mathrm{hr}$. on a boiling-water bath with $1 \cdot 1 \mathrm{~g}$. Girard's Reagent T (Girard \& Sandulesco, 1936) and $1.5 \mathrm{ml}$. glacial acetic acid. After cooling the flasks in ice, $10 \mathrm{~g}$. crushed ice and $30 \mathrm{ml}$. ice-cold water were added and then slowly, with thorough stirring, $9 \cdot 2 \mathrm{ml} .2 \cdot 5 \mathrm{~N}-\mathrm{NaOH}$. The mixtures were extracted 5 times with $50 \mathrm{ml}$. ether and the combined ether extracts were washed twice with $20 \mathrm{ml}$. portions of water, these washings being added to the original aqueous phases containing the ketonic fractions. The ether extracts were washed further with $20 \mathrm{ml} .0 \cdot 2 \mathrm{M}-\mathrm{NaHCO}_{3}$ and twice with $20 \mathrm{ml}$. water; these washings were discarded. The washed extracts were dried over $\mathrm{Na}_{2} \mathrm{SO}_{4}$ and evaporated to dryness to provide the non-ketonic fractions. The aqueous phases containing the Girard complexes of the ketones were acidified with $10 \mathrm{ml}$. $10 \mathrm{~N}-\mathrm{HCl}$ and allowed to stand for $16 \mathrm{hr}$. at room temperature. Ketones were extracted with $200 \mathrm{ml}$. and three $100 \mathrm{ml}$. portions of ether. The combined extracts were washed with $25 \mathrm{ml}$. $0 \cdot 2 \mathrm{M}-\mathrm{NaHCO}_{3}$ and three $25 \mathrm{ml}$. portions of water, dried over $\mathrm{Na}_{2} \mathrm{SO}_{4}$ and evaporated to dryness to yield the ketonic fractions.

The ketonic and non-ketonic fractions were then treated with digitonin in $90 \%(\mathrm{v} / \mathrm{v})$ aqueous ethanol for separation into $\alpha$ (not-precipitated)- and $\beta$ (precipitated)-fractions by the procedure described by Butler \& Marrian (1938), except that $24 \mathrm{hr}$. instead of $2 \mathrm{hr}$. were allowed for the formation of the insoluble digitonides (cf. Haslam \& Klyne, 1953). The weights of the various fractions so obtained are shown in Table 1.

\section{Investigation of fractions}

$\alpha$-Ketonic. This fraction from the incubation experiment (150 mg.) was chromatographed on alumina. Elution of the column with benzene, benzene-ether mixtures and finally ether yielded two main fractions. The first $(20.8 \mathrm{mg}$.), eluted by benzene-ether (9:1, by vol.), was slightly yellow and semicrystalline. After two crystallizations from aqueous ethanol, $16 \mathrm{mg}$. progesterone, identified by m.p., mixed m.p. and u.v. absorption spectrum in ethanol and conc. $\mathrm{H}_{2} \mathrm{SO}_{4}$, were obtained. The second fraction $56 \mathrm{mg}$., eluted by benzene-ether $(2: 8$, by vol.) and ether, was white and semicrystalline but melted over a wide range. It was suspected that this material consisted of a mixture of $3 \alpha$-hydroxypregnanones. On rechromatography, a number of semicrystalline fractions were obtained; the first fractions eluted by benzeneether $(2 \cdot 5: 7 \cdot 5$, by vol.) melted over the range 146$166^{\circ}$, while the later fractions had m.p.'s from 135$140^{\circ}$ to $140-144^{\circ}$. The intermediate fractions, though semicrystalline, melted over a very wide 
range of temperature. These fractions were therefore again chromatographed and a further separation into higher and lower melting fractions was achieved. The bulk of the material, however, still melted over a wide range.

The higher-melting fractions were combined, and after two crystallizations from aqueous methanol, $5 \mathrm{mg}$. thin plates, m.p. $172-174 \cdot 5^{\circ}$ were obtained. This substance did not depress the m.p. of authentic $3 \alpha$-hydroxy-5 $\alpha$-pregnan-20-one (m.p. 173-175 ${ }^{\circ}$; its acetate (m.p. $140-142^{\circ}$ ) mixed with the authentic acetate (m.p. 141-143 ${ }^{\circ}$ ) had m.p. 139-142 ${ }^{\circ}$. Comparison of infrared and u.v. spectra in conc. $\mathrm{H}_{2} \mathrm{SO}_{4}$ confirmed that the isolated material was $3 \alpha-$ hydroxy-5 $\alpha$-pregnan-20-one. experiment was white and semicrystalline but melted over a wide range. By chromatography, two main fractions were obtained; the first (15 mg.) eluted by benzeno-other (95:5, by vol.) had m.p. 178-192 and one crystallization from acetone gave $12 \mathrm{mg}$. shimmering, white plates, m.p. 198-200'. Admixture with authentic 5 $\alpha$-pregnane-3:20-dione (m.p. 199-200') did not depress the m.p. The identity of the infrared spectra and of u.v. spectra in conc. $\mathrm{H}_{2} \mathrm{SO}_{4}$ of the isolated material and those of $5 \alpha$-pregnane-3:20-dione proved conclusively that the isolated material was 5 $\alpha$-pregnane-3:20-dione. The digitonin-precipitable character of this dione has also been reported by Butenandt \& Mamoli (1935).

Table 1. Weights of fractions from incubation and 'control' experiments on treatment with Girard Reagent $T$ and digitonin

\begin{tabular}{|c|c|c|c|c|}
\hline & \multicolumn{4}{|c|}{$\begin{array}{l}\text { Neutral lipid extracts } \\
\text { Incubation } 560 \mathrm{mg} . \\
\text { 'Control' } 549 \mathrm{mg} \text {. }\end{array}$} \\
\hline $\begin{array}{l}\text { Incubation: } \\
\text { 'Control': }\end{array}$ & \multicolumn{2}{|c|}{$\begin{array}{l}\text { Ketonic fraction } \\
191 \mathrm{mg} . \\
304 \mathrm{mg} .\end{array}$} & \multicolumn{2}{|c|}{$\begin{array}{l}\text { Non-ketonic fract } \\
346 \mathrm{mg} . \\
214 \mathrm{mg} .\end{array}$} \\
\hline $\begin{array}{l}\text { Incubation: } \\
\text { 'Control': }\end{array}$ & $\begin{array}{l}\alpha-\text { Ketonic } \\
150 \mathrm{mg} . \\
294 \mathrm{mg} .\end{array}$ & $\begin{array}{l}\beta \text {-Ketonic } \\
40 \mathrm{mg} \text {. } \\
\text { Nil }\end{array}$ & $\begin{array}{l}\alpha \text {-Non-ketonic } \\
158 \mathrm{mg} . \\
86 \mathrm{mg} .\end{array}$ & $\begin{array}{r}\beta-\mathrm{No} \\
9 \\
10\end{array}$ \\
\hline
\end{tabular}

The lower-melting fractions, combined and crystallized from hexane, gave $16 \mathrm{mg}$. fine needles, m.p. $146 \cdot 5-149^{\circ}$. The substance yielded an acetate m.p. $97-100^{\circ}$ and a semicarbazone, m.p. 248-251 ${ }^{\circ}$. Mixed m.p. determinations with $3 \alpha$-hydroxy-5 $\beta$ pregnan-20-one (m.p. 147-149 ${ }^{\circ}$ ), its acetate (m.p. 99-101 ${ }^{\circ}$ ) and its semicarbazone (m.p. 249-250 indicated that the isolated material was $3 \alpha$ hydroxy-5 $\beta$-pregnan-20-one. This was confirmed by comparison of the infrared spectra.

The combined intermediate fractions $(25 \mathrm{mg}$. as judged by examination of the infrared spectrum of the material consisted of a mixture of the two $3 \alpha$-hydroxypregnan-20-ones containing approx. $17 \mathrm{mg}$. of the $5 \beta$-isomer and $5 \mathrm{mg}$. of the $5 \alpha-$ isomer (if it may be assumed that no other compound was present). No further separation of this material was attempted.

On chromatography of the $\alpha$-ketonic fraction from the 'control' only one main fraction was obtained. After one crystallization from hexane and one from aqueous ethanol $194 \mathrm{mg}$. progesterone, identified as above, were recovered.

$\beta$-Ketonic. No material was obtained from the 'control' in this fraction. That from the incubation
The second fraction (20.5 mg.) was eluted from the column by ether and had m.p. 184-190 . Crystallization from benzene-hexane ( $1: 2$, by vol.) gave $15.5 \mathrm{mg}$. of a product which melted at 193 $194^{\circ}$; mixed m.p. with authentic $3 \beta$-hydroxy-5 $\alpha$ pregnan-20-one (m.p. $193-195^{\circ}$ ) was 192-194 ${ }^{\circ}$; the acetate, m.p. $138-140^{\circ}$ did not depress the m.p. of the authentic acetate (m.p. 138-141 ${ }^{\circ}$ ). The identity of the material as $3 \beta$-hydroxy-5 $\alpha$-pregnan-20-one was confirmed by infrared spectrum and its u.v. spectrum in conc. $\mathrm{H}_{2} \mathrm{SO}_{4}$.

$\alpha-N o n-k e t o n i c$. Both the incubation and 'control' material in this fraction were dark brown gums. They were chromatographed on alumina using the gradient elution technique; the columns were eluted by an ethanol-benzene mixture ranging from $2 \%(v / v)$ to $5 \%(v / v)$ ethanol by a linear gradient over $200 \mathrm{ml}$. (cf. Lakshmanan, 1954). From the incubation experiment material, one semicrystalline fraction (46 mg.) was eluted at ethanol concns. from 3.75 to $4.5 \%$ (v/v). An attempt was made to separate this material into $5 \alpha$ - and $5 \beta$ pregnane-3 $\alpha: 20 \alpha$-diol by means of the solubility method of Kyle \& Marrian (1951). Only one crystalline substance (35 mg.) was obtained; this 
had m.p. 235-237.5 ${ }^{\circ}$ and mixed with 5 $\beta$-pregnane$3 \alpha: 20 \alpha$-diol $\left(236-238^{\circ}\right)$ the m.p. was $235-237^{\circ}$; an acetate prepared in the usual manner exhibited the double m.p. $162-164^{\circ}$ and $178-181^{\circ}$ characteristic of the diacetate of $5 \beta$-pregnane-3 $\alpha: 20 \alpha$-diol (cf. Verly et al. 1950). A mixture of the authentic diacetate (m.p. $162-163^{\circ}, 180-181^{\circ}$ ) and the acetate of the isolated material had m.p. 161-163 ${ }^{\circ}, 177-$ $180^{\circ}$. The identity of the isolated material as $5 \beta$ pregnane-3 $\alpha: 20 \alpha$-diol was finally established by determination of its infrared spectrum and u.v. spectrum in conc. $\mathrm{H}_{2} \mathrm{SO}_{4}$. The other fractions from this column and all fractions from the 'control' column were dark brown gums, readily soluble in small volumes of cold hexane. The fractions from the the number of steps in the purification procedure, quantitative recovery of steroids from the largescale experiment was not attempted. The most significant loss of material, apart from that normally associated with crystallization and adsorption chromatography, probably occurred during the hexane-aqueous methanol partition, since the lipids passing into the hexane would themselves have increased the solubility of the steroids in this phase. It is considered that the lower percentage recovery from the incubation experiment was due to the greater diversity of substances present as compared with the 'control' and was not due to the presence of a major metabolite not recovered by the isolation procedure employed.

Table 2. Steroids isolated from large-scale incubation and 'control' experiments $370 \mathrm{mg}$. progesterone; $450 \mathrm{~g}$. rabbit liver.

\begin{tabular}{|c|c|c|c|c|}
\hline \multirow[b]{2}{*}{ Steroid isolated } & \multicolumn{2}{|c|}{ After incubation } & \multicolumn{2}{|c|}{ From 'control' } \\
\hline & $\begin{array}{l}\text { Weight } \\
\text { (mg.) }\end{array}$ & $\begin{array}{l}\text { As percentage } \\
\text { of added } \\
\text { progesterone }\end{array}$ & $\begin{array}{l}\text { Weight } \\
\text { (mg.) }\end{array}$ & $\begin{array}{l}\text { As percentage } \\
\text { of added } \\
\text { progesterone }\end{array}$ \\
\hline $\begin{array}{l}5 \alpha \text {-Pregnane-3:20-dione } \\
\text { 3 } \alpha \text {-Hydroxy-5 } \alpha \text {-pregnan-20-one } \\
3 \beta \text {-Hydroxy-5 } \alpha \text {-pregnan-20-one } \\
3 \alpha \text {-Hydroxy-5 } \beta \text {-pregnan-20-one } \\
5 \beta \text {-Pregnane-3 } \alpha: 20 \alpha \text {-diol } \\
\text { Progesterone }\end{array}$ & $\begin{array}{l}12 \\
5(10)^{*} \\
15 \cdot 5 \\
16(33)^{*} \\
35 \\
16\end{array}$ & $\begin{array}{l}3 \cdot 2 \\
1 \cdot 4(2 \cdot 7)^{*} \\
4 \cdot 2 \\
4 \cdot 3(8 \cdot 9)^{*} \\
9 \cdot 5 \\
4 \cdot 3\end{array}$ & $\frac{Z}{E}$ & $\begin{array}{l}- \\
\frac{-}{52}\end{array}$ \\
\hline Totals & & $26.9(32.8)^{*}$ & - & 52 \\
\hline
\end{tabular}

* Figures in parentheses give the estimated amounts of these metabolites present on the basis of infrared analysis of the unresolved material from the $\alpha$-ketonic fraction.

incubation experiment were combined, acetylated and rechromatographed but no further crystalline material was isolated.

$\beta$-Non-ketonic. Both incubation and 'control' fractions were white and semicrystalline. A semiquantitative Liebermann-Burchard reaction using the conditions described by Kerr \& Bauld (1953) indicated that both fractions consisted almost entirely of cholesterol. Direct crystallization from ethanol yielded large plates, m.p. 145-147 ${ }^{\circ}$. Recrystallization from ether of the residue from the ethanol mother-liquors yielded fine needles, m.p. $146-148^{\circ}$. The residue from the mother liquors still consisted almost entirely of cholesterol. The total amounts of cholesterol isolated were, from the incubation experiments, $84 \mathrm{mg}$. and from the 'control', $90 \mathrm{mg}$. The identity of the material as cholesterol was established by mixed m.p., preparation of acetates and infrared spectroscopy.

For convenience, the results of the large-scale experiment are summarized in Table 2 ; the amounts of the substances isolated as a percentage of the total added progesterone are also given. Because of

\section{DISCUSSION}

The enzyme system in rabbit liver responsible for the reductive catabolism of progesterone appears to have similar properties to that in rat liver since both are activated by diphosphopyridine nucleotide (DPN), nicotinamide and citrate and neither is affected by absence of oxygen. Wiswell \& Samuels (1953) have suggested that citrate and isocitrate stimulate progesterone metabolism by liver in vitro by combining with inhibiting metal ions since addition of other chelating agents such as cysteine and cyanide also results in increased progesterone destruction. Tomkins \& Isselbacher (1954) have shown, however, that reduction of progesterone and other steroids by an enzyme system prepared from rat liver was increased by addition of reduced triphosphopyridine nucleotide (TPN) and that the reductive system can be coupled with isocitrateisocitric dehydrogenase or with glucose 6-phosphate-glucose 6-phosphate dehydrogenase. It seems probable, therefore, that the stimulatory 
effect of citrate on progesterone metabolism in homogenate can be explained by the following series of reactions:

$$
\text { Citrate } \rightleftharpoons \text { cis-aconitate } \rightleftharpoons \text { isocitrate })\left(\begin{array}{c}
\text { oxidized } \\
\mathrm{TPN}
\end{array}\right)\left(\begin{array}{l}
\text { reduced } \\
\text { progesterone } \\
\text { reduced }
\end{array}\right)
$$

Rabbit liver produces a greater complexity of metabolites than rat liver. In experiments with rat liver only metabolites of the $5 \alpha$-pregnane series were isolated, while rabbit liver has yielded both $5 \alpha$ - and $5 \beta$-pregnane derivatives with the latter predominating. Furthermore, in rabbit liver both $3 \alpha$ - and $3 \beta$-hydroxylated metabolites were produced and $5 \alpha$-pregnane-3:20-dione (5 $\alpha$-pregnanedione) and $3 \alpha$-hydroxy-5 $\alpha$-pregnan-20-one were minor meta- bolites, while from rat liver only a $3 \alpha$-hydroxyl derivative was isolated and $5 \alpha$-pregnanedione and $3 \alpha$-hydroxy-5 $\alpha$-pregnan-20-one were major metabolites (cf. Taylor, 1954a). Thus there exists a marked species difference in the metabolism of progesterone by the livers of these animals in vitro.

The generally accepted scheme for representing the metabolic reduction of progesterone involves arrangement of the metabolites in order of

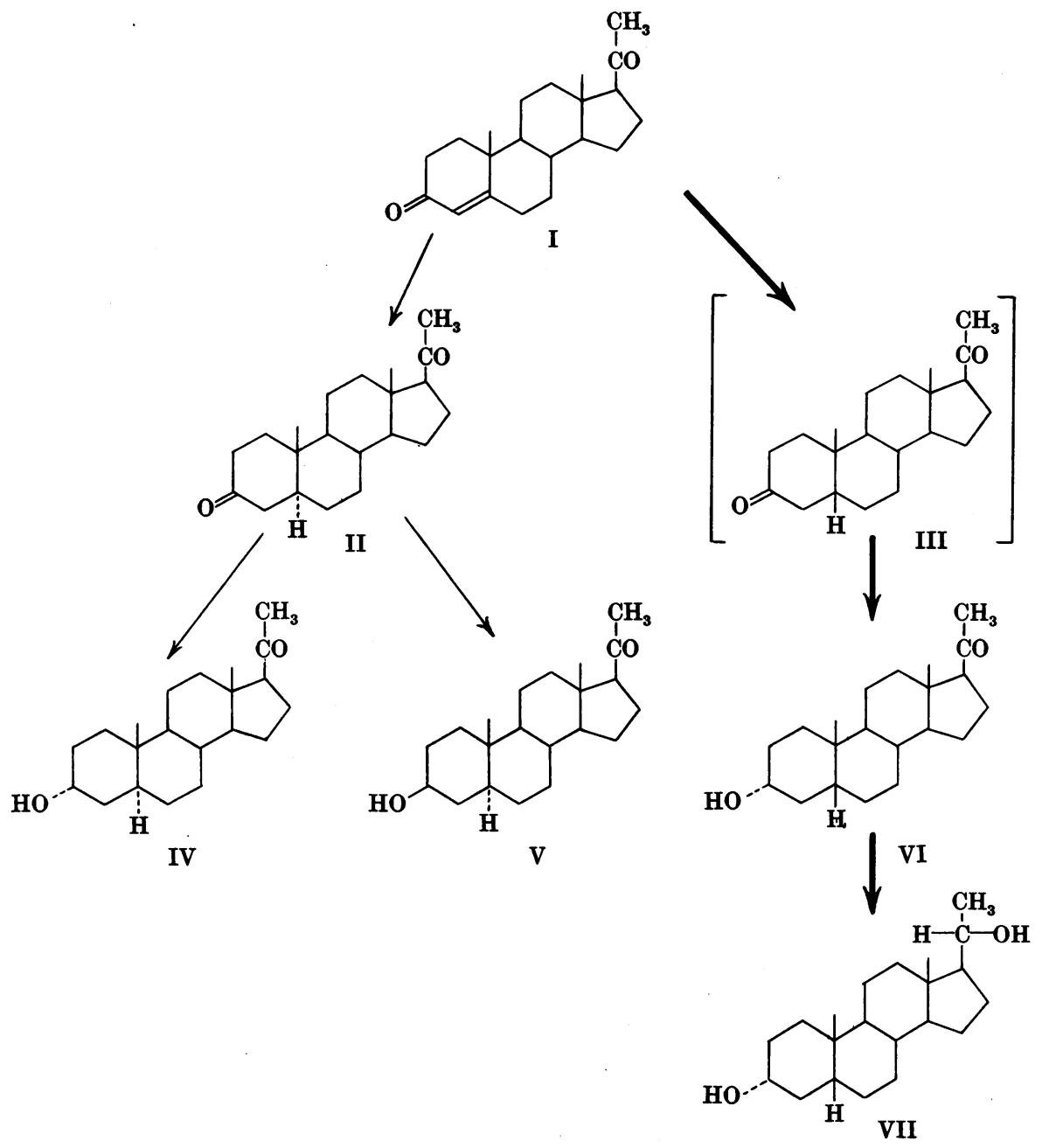

Fig. 3. Possible pathways of progesterone metabolism in rabbit liver. Heavy arrows indicate formation of major metabolites. 5 $\beta$-Pregnane-3:20-dione (III) is bracketed because it was not isolated. 
increasing state of reduction (cf. Lieberman \& Teich, 1953). This scheme is applied to the present experiment with rabbit liver in Fig. 3. Progesterone $(\mathrm{I})$ is reduced initially at the double-bond in ring. $A$ to yield $5 \alpha$ - and $5 \beta$-pregnane-3:20-dione ( $5 \alpha$ - and $5 \beta$ pregnanediones) (II and III) which undergo reduction at C-3 to the three 'pregnanolones', $3 \alpha-$ hydroxy-5 $\alpha$-pregnan-20-one (IV), 3 $\beta$-hydroxy-5 $\alpha$ pregnan-20-one $(\mathrm{V})$ and $3 \alpha$-hydroxy-5 $\beta$-pregnan20-one (VI); the latter is then reduced at C-20 to give $5 \beta$-pregnane-3 $\alpha: 20 \alpha$-diol ('pregnanediol') (VII). Since no $5 \beta$-pregnanedione was isolated from rabbit liver, it must be assumed that this steroid was reduced as rapidly as it was formed from progesterone.

Some explanation must be sought for the production of metabolites of both the $5 \alpha$ - and $5 \beta$-pregnane series having the $\alpha$-or $\beta$-configuration at C-3. This diversity of metabolites could be due either to the presence of a number of specific enzymies each yielding a specific metabolite or to fewer, nonspecific enzymes able to catalyse non-stereospecific reductions. Tomkins \& Isselbacher (1954) have purified from rat liver an enzyme preparation which reduces a variety of steroids having the $\alpha \beta$-unsaturated, 3-ketonic group in ring $A$ to $3 \alpha$-hydroxy-5 $\beta$ steroids only, in the presence of reduced triphosphopyridine nucleotide $\left(\mathrm{TPN}_{\text {red. }}\right)$. They suggest that this reduction proceeds by a two-stage process but that reduction of the saturated 3-ketone is so rapid that it does not accumulate in the system. In support of this suggestion they showed that the saturated 3-ketone is also reduced to the $3 \alpha$-hydroxyl derivative in the presence of reduced DPN (DPN red.) or $\mathrm{TPN}_{\text {red. }}$ and that this reaction is reversible in the presence of the oxidized form of TPN $\left(\mathrm{TPN}_{\text {oxid. }}\right)$ or DPN (DPN $\left.{ }_{\text {oxdd. }}\right)$, the overall reaction being: same source which acts only on $3 \beta$ - or $17 \beta$-hydroxylated $\mathrm{C}_{\mathbf{1 9}}$-steroids.

These findings support the opinion that reduction of $\alpha \beta$-unsaturated, 3-ketonic steroid hormones occurs by two-stage reduction in ring $A$ and also that the enzymes involved are specific for particular configurations at C-3 and C-5. They do not, however, provide absolute proof that this is so.

The possibility exists that the first step in progesterone reduction, at least in rabbit liver, involves a one-stage reduction to the 'pregnanolones'. While enzymes able to catalyse interconversion of saturated 3-ketones and the corresponding 3-hydroxylated compounds undoubtedly exist in tissues, they may play only a minor role in side reactions and may not actually be involved in the main one-stage addition of four hydrogen atoms to ring $A$. This alternative scheme as applied to rabbit liver is presented in Fig. 4. Progesterone (I) is reduced in one step to the three 'pregnanolones' (II-IV); the $3 \alpha$-hydroxy-5 $\beta$-pregnan-20-one (IV) which greatly predominates is further reduced at C-20 to give 'pregnanediol' (VI). By reoxidation of the pregnanolones, $5 \alpha$-pregnanedione $(\mathrm{V})$ is then produced.

The failure to isolate other reduction products of progesterone in the present experiment does not prove that others were not formed. It would appear from Table 2 that only substances formed to an extent of about $5 \%$ of the added progesterone would be detected by the isolation technique used. It is unlikely, however, that any $3 \beta$-hydroxy-5 $\beta$-pregnan-20-one was formed; this steroid has never been isolated from urine and the corresponding 'pregnanediol', $5 \beta$-pregnane-3 $\beta$ :20 $\alpha$-diol has only been tentatively identified in the urine from a case of adrenal hyperplasia (Mason \& Kepler, 1945). The absence of this steroid from the in vivo and in vitro

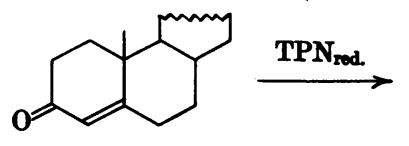

Also, Ungar \& Dorfman (1954) have shown that rabbit liver contains an enzyme, activated by DPN, which reduces 17 $\alpha: 21$-dihydroxy-5 $\beta$-pregnane-3:20:dione to $3 \alpha: 17 \alpha: 21$-trihydroxy-5 $\beta$-pregnan-20-one only.

A similar enzyme acting on $\mathrm{C}_{19}$-steroids has been demonstrated in a species of Pseudomonas and in animal tissues by Talalay \& Marcus (1954). This enzyme catalyses the reaction:

$$
\begin{aligned}
& \text { 3 } \alpha \text {-hydroxy-5 } \alpha \text {-androstan-17-one (androsterone) } \\
& \quad+\mathrm{DPN}_{\text {oxdd. }} \rightleftharpoons 5 \alpha \text {-androstane-3:17-dione }+\mathrm{DPN}_{\text {red. }} .
\end{aligned}
$$

At equilibrium, the androsterone predominates. This enzyme is quite distinct from another from the

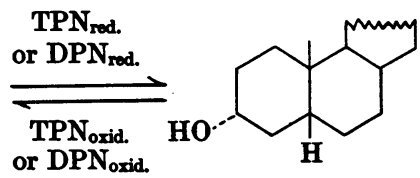

metabolites of progesterone may find explanation in the fact that the $5 \beta: 3 \beta$ configuration is the least stable and the most sterically hindered of the four possible forms isomeric about C-5 and having a substituent at C-3 (Barton, 1953).

It may also be of significance that the major metabolite of progesterone, $5 \beta$-pregnane-3 $\alpha: 20 \alpha$ diol, has the less stable configuration at C-5, while the configuration at C-3 is of the more stable and less-hindered type. Professor Barton has suggested to the author that this could be explained by supposing that reductions at C-3 proceed by a different mechanism from that resulting in the formation of the unstable configuration at C-5 by 
reduction of the double bond. Caution must be exercised, however, in attempting to interpret steroid reactions in biological systems in terms of the stability of particular conformations (cf. Ralls, Saunders, Raymond \& Riegel, 1954), for there are many examples in which the more unstable and/or sterically hindered forms predominate. For instance, in direct contrast to $5 \beta$-pregnane- $3 \alpha: 20 \alpha$-diol, $3 \alpha$-hydroxy-5 $\alpha$-androstan-17-one (androsterone) has the more stable configuration at C-5 and the nized products. This possibility may help to explain the discrepancy between the amount of incubated hormone and the amounts of metabolites isolated.

The relationship between the present in vitro findings and the metabolism of progesterone by the rabbit in vivo must await more systematic in vivo studies with this animal. Though both the present in vitro experiments and in vivo studies (see Introduction for references) indicate that $5 \beta$-pregnane$3 \alpha: 20 \alpha$-diol is the major metabolite of progesterone

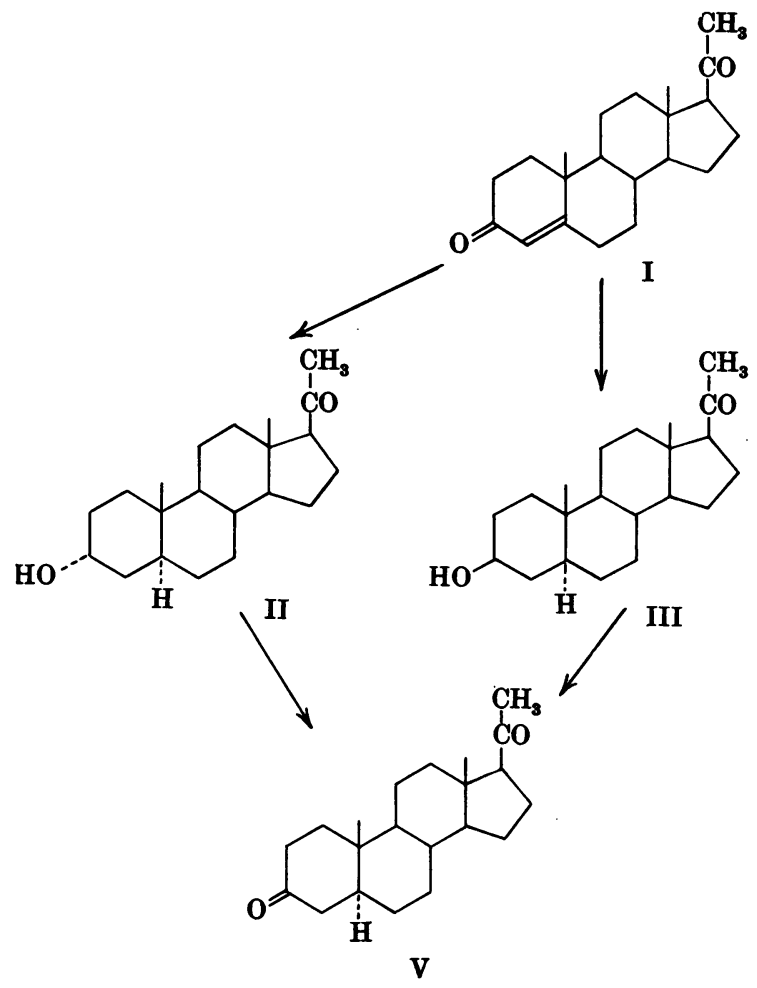

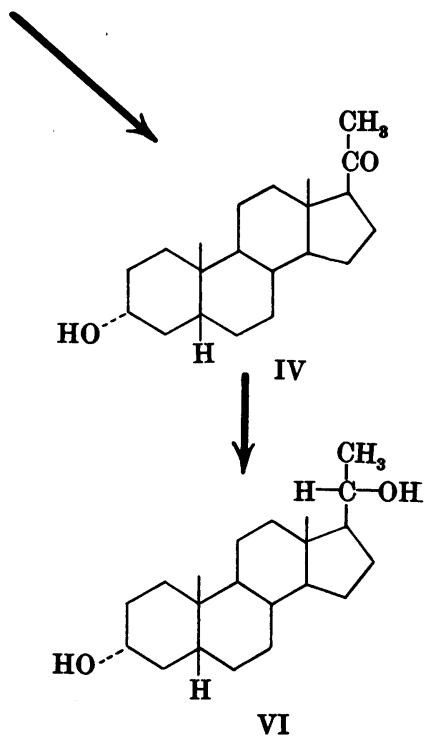

Fig. 4. An alternative pathway of progesterone metabolism in rabbit liver. Heavy arrows indicate formation of major metabolites.

hydroxyl group in the more hindered axial conformation and yet this steroid is a major metabolite of testosterone. Also, 3 $\alpha$-hydroxy-5 $\alpha$-pregnan-20-one has the 3-hydroxyl in the axial conformation and yet is a major metabolite of progesterone in rat liver (Taylor, 1954a) and appreciable amounts are formed by rabbit liver. Catalytic hydrogenation of progesterone yields mainly products of the more stable 5 $\alpha$-pregnane series (see Pearlman, 1948, for references), whereas in most biological reductions of progesterone, the less stable $5 \beta$-pregnanes appear to predominate. It is possible that $5 \alpha$-pregnane derivatives are actually formed to a greater extent but are more quickly degraded to as yet unrecog- in the rabbit, it does not follow that in vivo metabolism of the hormone is confined to the liver. The ability of other organs to metabolize progesterone must be taken into account. Thus, Ralls et al. (1954) isolated $3 \alpha$-hydroxy-5 $\beta$-pregnan-20-one and $5 \beta$ pregnane-3 $\alpha: 20 \beta$-diol after perfusion of $5 \beta$-pregnanedione through ox adrenals, and Hayano, Linberg, Wiener, Rosenkrantz \& Dorfman (1954) obtained 20 $\beta$-hydroxy-pregn-4-en-3-one after incubation of progesterone with ox corpora lutea. That the placenta itself may be involved in progesterone metabolism is indicated by the isolation of $3 \beta$ hydroxy-5 $\alpha$-pregnan-20-one and 'pregnanediol' from this organ (Pearlman \& Cerceo, 1952). The 
role of progesterone in the biosynthesis of adrenocortical hormones (Brownie \& Grant, 1954) must also be considered in evaluation of progesterone metabolism in vivo.

An additional complication in in vivo experiments is the possibility of excretion of metabolites via the bile. It is well established that steroids can be excreted by this route in a number of species (see Lieberman \& Teich, 1953 for references) and the presence of 'pregnanediol' in the faeces of rabbits to which progesterone had been administered orally (Hoffman \& Browne, 1942) suggests that in these animals also, biliary excretion of steroid hormone metabolites occurs.

A great number of methods has been devised for the determination of urinary 'pregnanediol' (cf. Valle, 1954) and the results of such determinations have been used as an index of endogenous progesterone production. In view of the complexity of progesterone catabolism and the possibility that metabolites may be excreted in the faeces as well as in the urine, the results of urinary 'pregnanediol' determinations must be interpreted with great caution.

\section{SUMMARY}

1. It has been demonstrated that rabbit liver contains an enzyme system able to metabolize progesterone in vitro. Metabolism is increased by addition of diphosphopyridine nucleotide and nicotinamide or of citrate to the reaction mixture; it is not inhibited under anaerobic conditions.

2. In a large-scale experiment in which progesterone was incubated with a suspension of disintegrated liver with added nicotinamide and citrate, $33 \%$ of the added steroid was accounted for by the isolation of $5 \alpha$-pregnane-3:20-dione, the $3 \alpha$ - and


pregnan-20-one, $5 \beta$-pregnane-3 $\alpha: 20 \alpha$-diol and unchanged progesterone.

3. The significance of these findings has been discussed.

The author wishes to acknowledge the gifts of steroids from various colleagues and especially the generosity of Dr C. L. Hewett, Organon Laboratories Ltd., Newhouse, Lanarkshire, who supplied the progesterone used in this work. He is most grateful to Dr A. E. Kellie, Courtauld Institute of Biochemistry, Middlesex Hospital, London, and to Dr L. J. Bellamy, Chemical Inspectorate, Ministry of Supply, London for the determinations of infrared spectra. This work was carried out during the tenure of a Senior Luccock Research Fellowship.

\section{REFERENCES}

Barton, D. H. R. (1953). J. chem. Soc. p. 1027.

Brownie, A. C. \& Grant, J. K. (1954). Biochem. J. 58, 218.

Butenandt, A. \& Mamoli, L. (1935). Ber. dtsch.chem. Ges. 68, 1847.

Butler, G. C. \& Marrian, G. F. (1938). J. biol. Chem. 124, 237.

Dorfman, R. I. \& Ungar, F. (1953). Metabolism of Steroid Hormones. Minneapolis: Burgess Publishing Co.

Girard, A. \& Sandulesco, G. (1936). Helv. chim. acta, 19, 1095. Haslam, R. M. \& Klyne, W. (1953). Biochem. J. 55, 340.

Hayano, M., Linberg, M. C., Wiener, M., Rosenkrantz, H. \& Dorfman, R. I. (1954). Endocrinology, 55, 326.

Heard, R. D. H., Bauld, W. S. \& Hoffman, M. M. (1941). J. biol. Chem. 141, 709.

Hoffman, M. M. (1942). Canad. med. Ass. J. 47, 424.

Hoffman, M. M. \& Browne, J. S. L. (1942). Fed. Proc. $1,41$.

Kerr, L. M. H. \& Bauld, W. S. (1953). Biochem. J. 55, 872.

Kyle, T. I. \& Marrian, G. F. (1951). Biochem. J. 49, 80.

Lakshmanan, T. K. (1954). Recent Progr. Hormone Res. 9, 179.

Lieberman, S. \& Teich, S. (1953). Pharm. Rev. 5, 285.

Marrian, G. F. \& Gough, N. (1946). Biochem. J. 40, 376.

Mason, H. L. \& Kepler, E. J. (1945). J. biol. Chem. 161, 235.

Pearlman, W. H. (1948). In The Hormones, ed. by Pincus, G. \& Thimann, K. V., vol. 1, p. 407. New York: Academic Press.

Pearlman, W. H. \& Cerceo, E. (1952). J. biol. Chem. 194, 807.

Ralls, J. W., Saunders, F. J., Raymond, A. L. \& Riegel, B. (1954). J. biol. Chem. 210, 709.

Reichstein, T. \& Shoppee, C. W. (1949). Disc. Faraday Soc. 7, 305.

Riegel, B., Hartop, W. L. jun. \& Kittinger, G. W. (1950). Endocrinology, 47, 311.

Sutherland, E. S. \& Marrian, G. F. (1947). Biochem. J. 41, 193.

Talalay, P. \& Marcus, P. I. (1954). Nature, Lond., 173, 1189.

Taylor, W. (1954a). Biochem. J. 56, 463.

Taylor, W. (1954b). Biochim. biophys. acta, 15, 592.

Tomkins, G. \& Isselbacher, K. J. (1954). J. Amer. chem. Soc. 76, 3100.

Ungar, F. \& Dorfman, R. I. (1954). J. Amer. chem. Soc. 76, 1197.

Valle, G. (1954). In La Fonction Luteale (Publication des Colloques sur la Fonction Luteale; April, 1954). Paris: Masson and Co.

Verly, W. G., Sommerville, I. F. \& Marrian, G. F. (1950). Biochem. J. 46, 186.

Westphal, U. (1942). Hoppe-Seyl. Z. 271, 1.

Wiswell, J. G. \& Samuels, L. T. (1953). J. biol. Chem. 201, 155. 